\title{
Effect of Walking Speeds on Complexity of Plantar Pressure Patterns
}

\author{
Ben-Yi Liau, ${ }^{1}$ Fu-Lien Wu, ${ }^{2}$ Yameng Li, ${ }^{3}$ Chi-Wen Lung $\mathbb{D}^{2,4}$ Ayman A. Mohamed, ${ }^{2,5}$ \\ and Yih-Kuen Jan $\mathbb{D}^{2}$ \\ ${ }^{1}$ Department of Biomedical Engineering, Hungkuang University, Taichung 433304, Taiwan \\ ${ }^{2}$ Rehabilitation Engineering Lab, Department of Kinesiology and Community Health, \\ University of Illinois at Urbana-Champaign, Champaign, IL 61820, USA \\ ${ }^{3}$ College of Physical Education and Sports, Beijing Normal University, Beijing 100875, China \\ ${ }^{4}$ Department of Creative Product Design, Asia University, Taichung 41354, Taiwan \\ ${ }^{5}$ Department of Basic Sciences, Faculty of Physical Therapy, Beni-Suef University, Beni Suef 62511, Egypt
}

Correspondence should be addressed to Yih-Kuen Jan; yjan@illinois.edu

Received 16 June 2021; Accepted 21 August 2021; Published 29 August 2021

Academic Editor: Dan Selişteanu

Copyright (C) 2021 Ben-Yi Liau et al. This is an open access article distributed under the Creative Commons Attribution License, which permits unrestricted use, distribution, and reproduction in any medium, provided the original work is properly cited.

\begin{abstract}
Various walking speeds may induce different responses on the plantar pressure patterns. Current methods used to analyze plantar pressure patterns are linear and ignore nonlinear features. The purpose of this study was to analyze the complexity of plantar pressure images after walking at various speeds using nonlinear bidimensional multiscale entropy $\left(\mathrm{MSE}_{2 \mathrm{D}}\right)$. Twelve participants (age: $27.1 \pm 5.8$ years; height: $170.3 \pm 10.0 \mathrm{~cm}$; and weight: $63.5 \pm 13.5 \mathrm{~kg}$ ) were recruited for walking at three speeds (slow at $1.8 \mathrm{mph}$, moderate at $3.6 \mathrm{mph}$, and fast at $5.4 \mathrm{mph}$ ) for 20 minutes. A plantar pressure measurement system was used to measure plantar pressure patterns. Complexity index (CI), a summation of $\mathrm{MSE}_{2 \mathrm{D}}$ from all time scales, was used to quantify the changes of complexity of plantar pressure images. The analysis of variance with repeated measures and Fisher's least significant difference correction were used to examine the results of this study. The results showed that CI of plantar pressure images of $1.8 \mathrm{mph}(1.780)$ was significantly lower compared with $3.6(1.790)$ and $5.4 \mathrm{mph}(1.792)$. The results also showed that CI significantly increased from the $1^{\text {st }} \mathrm{min}(1.780)$ to the $10^{\text {th }} \mathrm{min}(1.791)$ and $20^{\text {th }} \mathrm{min}(1.791)$ with slow walking $(1.8 \mathrm{mph})$. Our results indicate that slow walking at $1.8 \mathrm{mph}$ may not be good for postural control compared with moderate walking $(3.6 \mathrm{mph})$ and fast walking $(5.4 \mathrm{mph})$. This study demonstrates that bidimensional multiscale entropy is able to quantify complexity changes of plantar pressure images after different walking speeds.
\end{abstract}

\section{Introduction}

Postural control is a complex process for maintaining the orientation and balance of human body during upright position and movements in activities of daily living [1-3]. Various methods have been used to evaluate human postural control, including center of mass, center of gravity, center of pressure, ground reaction force, and plantar pressure patterns [1-3]. Plantar pressure patterns (e.g., peak plantar pressure and plantar pressure gradient) during walking are resulted from the ground reaction force acting on the plantar foot. Research studies have shown that abnormal plantar pressure patterns may reflect underlying musculoskeletal and neurological disorders $[4,5]$.

Common analyses of plantar pressure patterns include average pressure, peak pressure, force value, and contact area $[6,7]$. Recently, researchers have indicated that these traditional methods may not fully characterize abnormal changes of postural control associated with aging or agingrelated conditions $[4,5]$. Research findings showed that using nonlinear analyses (e.g., irregularity and complexity) may be more effective than linear analyses to detect pathological changes of biological signals [8-10]. Costa et al. proposed a new nonlinear algorithm multiscale entropy 
(MSE) to analyze biological signals with limited length [11-13]. MSE is able to assess the complexity level of signal using a range of temporal scales. MSE with coarse-grained time series could represent the complexity of the system dynamics by using different time scales.

Complexity of a biosignal signal could reflect the condition of underlying information and structure. Generally, normal conditions have higher complexity, and aging and pathological conditions reduce complexity [11-13]. MSE is widely used in various medical applications due to its ability to correct erratic estimations of some pathological conditions using traditional, entropy-based methods [11-13]. Recently, MSE has been applied to extract the characterizations of various physiological time-series signals, such as RR interval, EEG, and center of pressure [12-16]. On the other hand, some researchers proposed algorithms to improve limitations of MSE output for higher entropy reliability due to reduction of variance from coarse-graining procedure by the elimination of the fast temporal scales $[13,17,18]$.

Bidimensional multiscale entropy $\left(\mathrm{MSE}_{2 \mathrm{D}}\right)$ was introduced by Silva and colleagues to overcome the limitation of one-dimensional MSE for analyzing two-dimensional images [19-21]. The $\mathrm{MSE}_{2 \mathrm{D}}$ algorithm is based on the original MSE and is an extension of MSE for two-dimensional data, such as biomedical images [19-22]. The $\mathrm{MSE}_{2 \mathrm{D}}$ algorithm has not been applied widely in various physiological conditions yet and may be used to detect complexity changes of plantar pressure during different pathophysiological conditions. Traditionally, gait pattern assessments, including plantar pressure patterns, are analyzed using linear methods [23]. Plantar pressure patterns may consist of linear and nonlinear components. However, to the best of our knowledge, there is no study assessing the complexity of plantar pressure patterns.

The objective of this study was to apply the recently proposed bidimensional multiscale entropy $\left(\mathrm{MSE}_{2 \mathrm{D}}\right)$ to assess complexity changes of plantar pressure patterns after walking at different speeds. In this study, we examined the change of complexity of plantar pressure images in response to different walking speeds by using bidimensional multiscale entropy $\left(\mathrm{MSE}_{2 \mathrm{D}}\right)$. The study aimed to examine the hypothesis of fast walking speeds at 3.6 and $5.4 \mathrm{mph}$ which would reduce complexity of plantar pressure images compared with slow walking speed at $1.8 \mathrm{mph}$. The findings from bidimensional multiscale entropy could help understand the effect of various walking speeds on plantar pressure and postural control.

\section{Material and Methods}

A repeated measures design was used in this study including 3 speeds (slow at $1.8 \mathrm{mph}$, moderate at $3.6 \mathrm{mph}$, and fast at $5.4 \mathrm{mph}$ ) for 20 minutes. The rationale to choose these 3 speeds is to characterize common walking and running speeds in people at risk for plantar tissue injury, including slow to normal walking speed at $1.8 \mathrm{mph}$, brisk walking speed at $3.6 \mathrm{mph}$, and slow running speed at $5.4 \mathrm{mph}$ [24]. This study was part of a larger project investigating plantar skin blood flow and plantar tissue in response to various walking intensities [24].

2.1. Subjects. Healthy subjects between 18 and 45 years of age were recruited from the university and nearby community. Exclusion criteria were active foot ulcers, diabetes, vascular diseases, hypertension, and inability of walking for $20 \mathrm{~min}$ independently, inability of walking at the speed of $5.4 \mathrm{mph}$ independently, or use of vasoactive medications. Each subject signed the informed consent approved by the University of Illinois at Urbana-Champaign Institutional Review Board before the screening and experimental procedures. Twelve healthy subjects (5 males and 7 females) were recruited in this study. The demographic data (mean \pm standard deviation) were age: $27.1 \pm 5.8$ years; height: $170.3 \pm 10.0 \mathrm{~cm}$; and weight: $63.5 \pm 13.5 \mathrm{~kg}$. All examinations were performed in the Rehabilitation Engineering Laboratory at the University of Illinois at UrbanaChampaign. Room temperature was fixed at $24 \pm 2^{\circ} \mathrm{C}$. All subjects relaxed in the supine position for at least 30 minutes prior to testing to stabilize the baseline elastography of plantar soft tissue and acclimate themselves to the room temperature.

2.2. Experimental Procedures. An F-scan system (Tekscan, South Boston, MA) was used to measure the plantar pressure data of the right foot in standardized shoes during each of 3 walking protocols [24]. A suitable pair of standard shoes and socks (Altrex, Teaneck, NJ, USA) with F-scan in-shoe sensors between the socks and the insoles was prepared for the participants [25]. An F-scan in-shoe sensor contains 960 sensing elements. The size of each sensing element is $5.08 \mathrm{~mm} \times 5.08 \mathrm{~mm}$. Before the walking trial, participants would walk for 3 to 5 minutes to get familiarized with the standard shoes. The sampling rate was $300 \mathrm{~Hz}$. The subjects walked at the speed of $1.8 \mathrm{mph}$ for 20 minutes at the first visit. All participants returned to the lab for performing $3.6 \mathrm{mph}$ and $5.4 \mathrm{mph}$ walking at the second and third visits, respectively. Each visit was separated between $7 \pm 2$ days. Figure 1 shows examples of plantar pressure images after walking at three speeds.

2.3. $M S E_{2 D}$ Analysis. Multiscale entropy (MSE) uses the algorithm of Sample Entropy to estimate the regularity in different time scales. $\mathrm{MSE}_{2 \mathrm{D}}[19-21,26]$ is derived from the one-dimensional MSE and is composed of two processes:

(i) The $2 \mathrm{D}$ coarse-graining procedure was derived as a set of time series on different time scales represented by equation (1). For a plantar pressure image $u$ with width $W$, and height $H$, the coarse-grained time series is computed as

$$
y_{i, j}^{(\tau)}=\frac{1}{\tau^{2}} \sum_{k=(i-1)}^{k=i \tau} \sum_{\tau+1}^{l=j \tau} U_{k, l},
$$

where $1 \leq i \leq(H / \tau)$ and $1 \leq j \leq(W / \tau) . \tau$ is the scale factor. When $\tau=1$, the coarse-grained plantar 


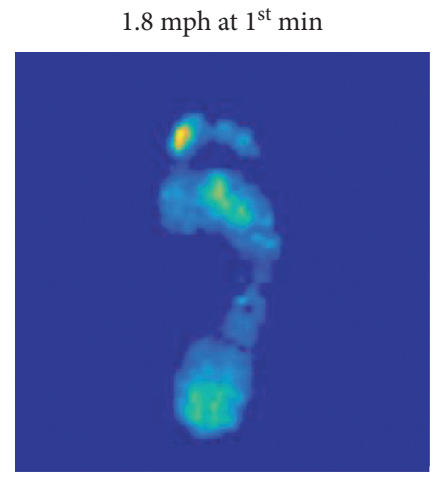

(a)

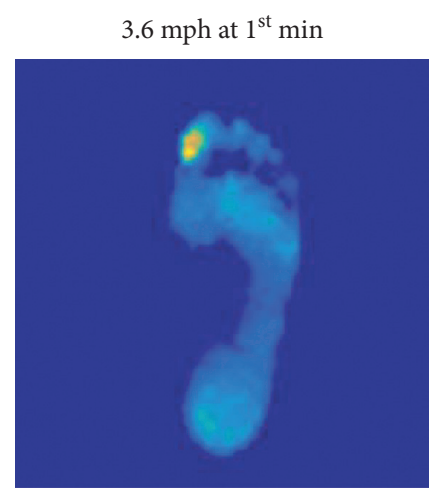

(d)

$5.4 \mathrm{mph}$ at $1^{\text {st }} \mathrm{min}$

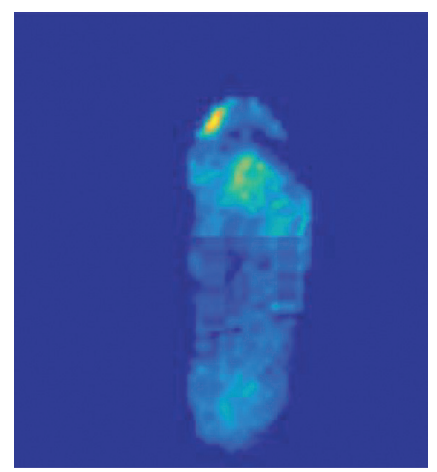

(g)

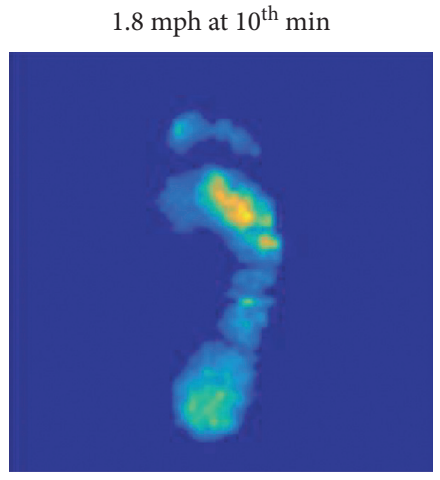

(b)

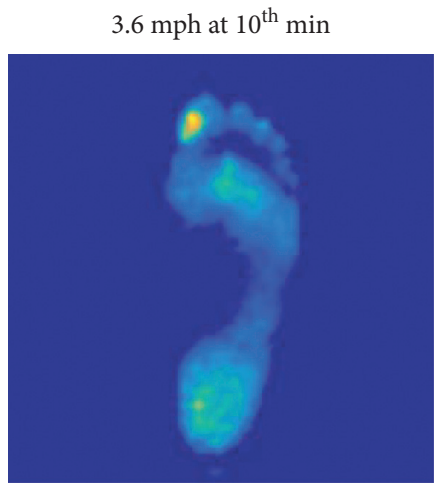

(e)

$5.4 \mathrm{mph}$ at $10^{\text {th }} \mathrm{min}$

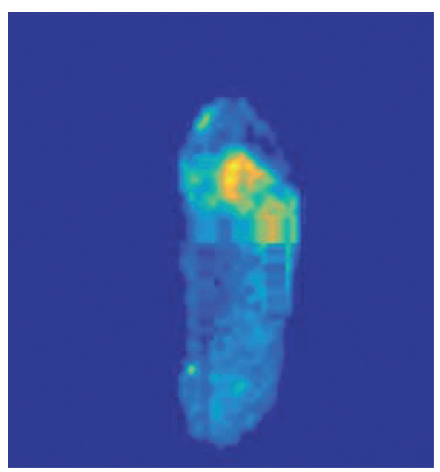

(h)

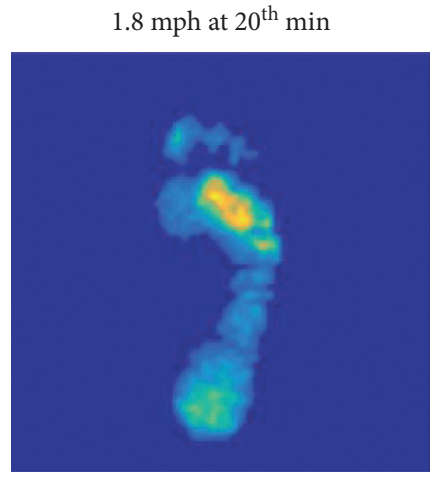

(c)

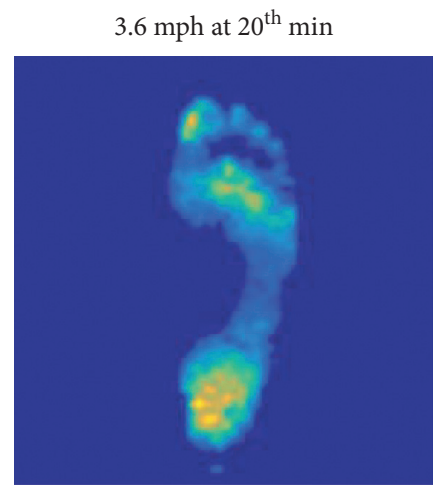

(f)

$5.4 \mathrm{mph}$ at $20^{\text {th }} \mathrm{min}$

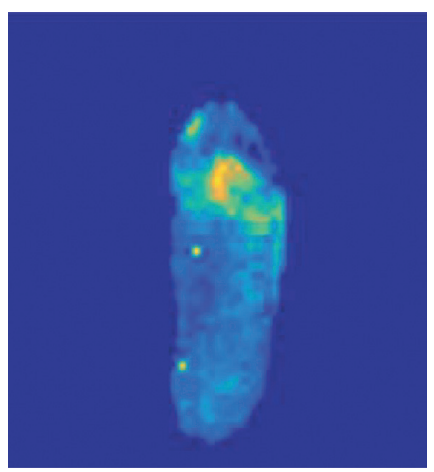

(i)

Figure 1: Examples of plantar pressure images after different walking speeds. Plantar pressure patterns at the $1^{\text {st }} \mathrm{min}(\mathrm{a}), 10^{\text {th }} \mathrm{min}(\mathrm{b})$, and $20^{\text {th }} \mathrm{min}(\mathrm{c})$ during walking at $1.8 \mathrm{mph}$. Plantar pressure images at the $1^{\text {st }} \mathrm{min}(\mathrm{d}), 10^{\text {th }} \mathrm{min}(\mathrm{e})$, and $20^{\text {th }} \mathrm{min}(\mathrm{f})$ during walking at $3.6 \mathrm{mph}$. Plantar pressure patterns at the $1^{\text {st }} \mathrm{min}(\mathrm{g}), 10^{\text {th }} \mathrm{min}(\mathrm{h})$, and $20^{\text {th }} \mathrm{min}$ (i) during walking at $5.4 \mathrm{mph}$.

pressure image $\left\{y^{(1)}\right\}$ corresponds to the original image. The width of the coarse-grained image $\left\{y^{(\tau)}\right\}$ is $W / \tau$, and the height is $H / \tau$.

For a plantar pressure image $u$, let $x_{m}(i, j)$ be the $m$ length square window with origin at $u(i, j): x_{m}(i, j)$ is the set of pixels ranging from columns $j$ to $j+m-1$ and lines $i$ to $i+m-1$. Let $N_{m}$ be the total number of square windows within $u$ that can be generated for both $m$ and $m+1$ size: $N_{m}=(W-m) \times(H-m)$.

(ii) Via the coarse-grained procedure, two-dimensional Sample Entropy ( $\operatorname{SampEn}_{2 \mathrm{D}}$ ) for a similarity threshold $r$ could be obtained by the following equation:

$$
\operatorname{SampEn}_{2 \mathrm{D}}=-\ln \frac{U^{m+1}(r)}{U^{m}(r)},
$$

where

$$
\begin{gathered}
U^{m}(r)=\frac{1}{N_{m}} \sum_{i=1 ; j=1}^{i=H-m ; j=W-m} U_{i, j}^{m}(r), \\
U^{m+1}(r)=\frac{1}{N_{m}} \sum_{i=1 ; j=1}^{i=H-m ; j=W-m} U_{i, j}^{m+1}(r),
\end{gathered}
$$


and

$$
\begin{aligned}
U_{i, j}^{m}(r) & =\frac{\left[\# \text { of } x_{m}(a, b) \mid d\left[x_{m}(i, j), x_{m}(a, b)\right] \leq r\right]}{N_{m}-1}, \\
U_{i, j}^{m+1}(r) & =\frac{\left[\# \text { of } x_{m+1}(a, b) \mid d\left[x_{m+1}(i, j), x_{m+1}(a, b)\right] \leq r\right]}{N_{m}-1},
\end{aligned}
$$

where $a$ and $b$ range from 1 to $H-m$ and from 1 to $W-m$, respectively, and $(a, b) \neq(i, j)$; distance $d$ is defined as

$$
\begin{aligned}
d\left[x_{m}(i, j), x_{m}(a, b)\right]= & \max (\mid u(i+k, j+l) \\
& -u(a+k, b+l) \mid),
\end{aligned}
$$

where $k$ and $l$ range from 0 to $m-1$.

Therefore, $\mathrm{MSE}_{2 \mathrm{D}}$ with the time scale $\tau$ can be accumulated with $\mathrm{SampEn}_{2 \mathrm{D}}$ by

$$
\operatorname{MSE}_{2 \mathrm{D}}(u, \tau, m, r)=\operatorname{SampEn}_{2 \mathrm{D}}\left(y^{(\tau)}, m, r\right) .
$$

At the last, the complexity index (CI) can be obtained from the summation of $\operatorname{SampEn}_{2 \mathrm{D}}$ with the scale factors 1 to the maximum:

$$
C I_{\tau}=\sum_{i=1}^{\tau} \operatorname{SampEn}_{2 \mathrm{D}}(i)
$$

The baseline demographic data were reported with descriptive statistics. The analysis of variance (ANOVA) with repeated measures was used to compare the CI between 3 speeds $(1.8,3.6$, and $5.4 \mathrm{mph})$. Fisher's least significant difference correction was used for pairwise comparisons of the CI between three walking speeds $(1.8,3.6$, and $5.4 \mathrm{mph})$. The correction was used to overcome multiple comparison issues in this repeated measures study. The significant level was set as 0.05 . All statistical tests were performed using SPSS 26 (IBM, Somers, NY). The CI was calculated using the MATLAB R2019b (MathWorks, Inc., Natick, MA, USA).

\section{Results}

Figure 2 shows the $\mathrm{MSE}_{2 \mathrm{D}}$ values from the time scales $\tau=1$ to 5 at the $1^{\text {st }} \mathrm{min}, 10^{\text {th }} \mathrm{min}$, and $20^{\text {th }}$ min during $1.8 \mathrm{mph}$ walking speed. It was found that at lower time scales, $\tau=1$ and $2, \mathrm{MSE}_{2 \mathrm{D}}$ values significantly increased with longer walking durations $\left(\tau=1,1^{\text {st }} \mathrm{min}\right.$ vs. $10^{\text {th }} \mathrm{min}=0.297$ vs. $0.305 ; 1^{\text {st }} \mathrm{min}$ vs. $20^{\text {th }} \min =0.297$ vs. $0.303, p<0.05 ; \tau=2$, $1^{\text {st }}$ min vs. $10^{\text {th }} \min =0.361$ vs. $0.364,1^{\text {st }} \min$ vs. $20^{\text {th }} \min =0.361$ vs. $\left.0.364, p<0.05\right)$. MSE 2 D did not significantly change with the time scales 3 to 5 . During 3.6 and $5.4 \mathrm{mph}$ walking speed, $\mathrm{MSE}_{2 \mathrm{D}}$ did not significantly change across all conditions (from the time scales $\tau=1$ to 5 at the $1^{\text {st }} \mathrm{min}, 10^{\text {th }} \mathrm{min}$, and $20^{\text {th }} \mathrm{min}$ ).

Figure 3 shows the complexity index values at the $1^{\text {st }} \mathrm{min}, 10^{\text {th }} \mathrm{min}$, and $20^{\text {th }}$ min during 3 walking speeds. During the walking speed of $1.8 \mathrm{mph}$, CI values significantly increased with walking speed $(p<0.05)$. There was a trend that $\mathrm{CI}$ increased with time at $1^{\mathrm{st}} \mathrm{min}, 10^{\text {th }} \mathrm{min}$, and $20^{\text {th }} \mathrm{min}$

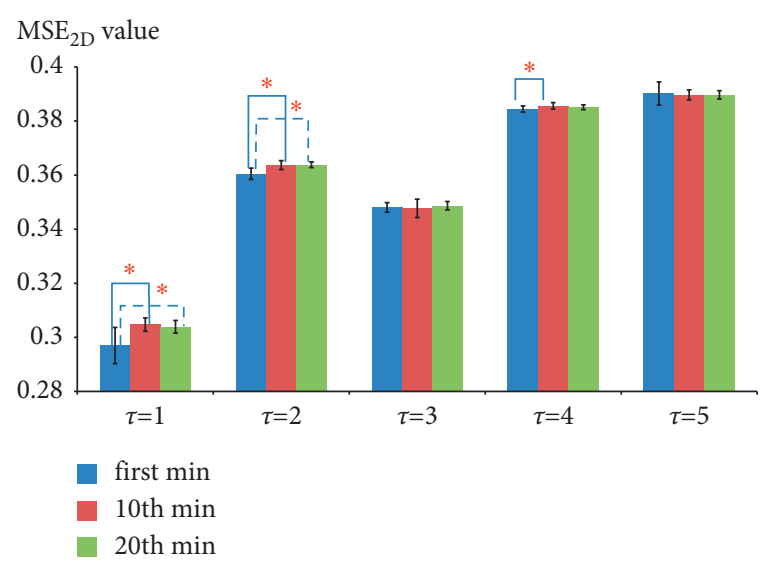

Figure 2: $\mathrm{MSE}_{2 \mathrm{D}}$ values of plantar pressure images from the time scales $\tau=1$ to 5 at the $1^{\text {st }} \mathrm{min}, 10^{\text {th }} \mathrm{min}$, and $20^{\text {th }} \mathrm{min}$ during $1.8 \mathrm{mph}$ speed. *indicates $p<0.05$.

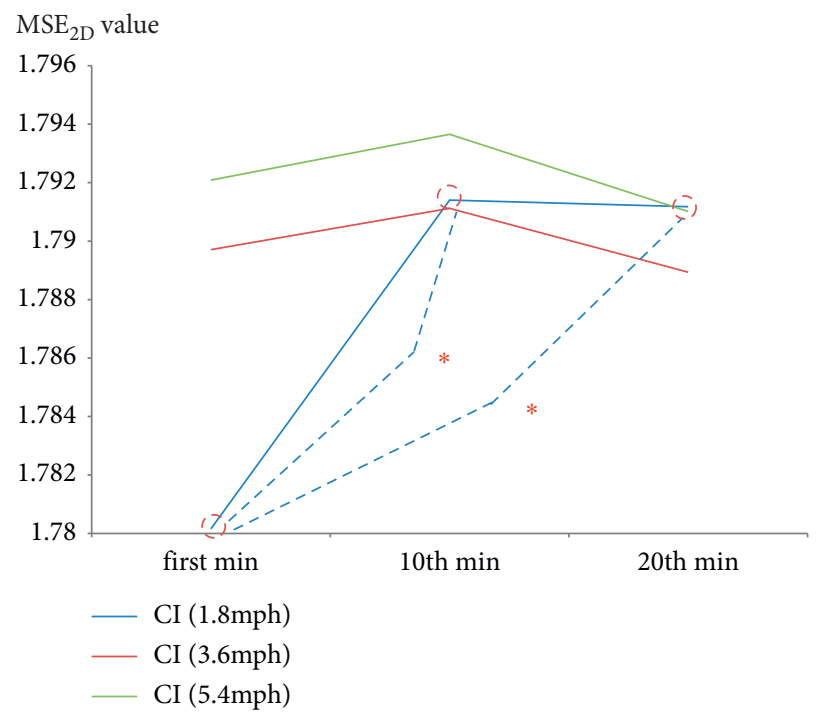

FIgURE 3: Complexity index (a summation of all time scales of $\mathrm{MSE}_{2 \mathrm{D}}$ values) of plantar pressure images at the $1^{\text {st }} \mathrm{min}, 10^{\text {th }} \mathrm{min}$, and $20^{\text {th }}$ min during three walking speeds $(1.8,3.6$, and $5.4 \mathrm{mph}$ ). *indicates $p<0.05$.

during $1.8 \mathrm{mph}$ speed $\left(\mathrm{CI}_{1 \mathrm{st} \min }=1.780, \mathrm{CI}_{10 \mathrm{th} \min }=1.791\right.$, and $\left.\mathrm{CI}_{20 \text { th } \min }=1.791\right)$. CI values of faster walking speeds, 3.6 $\mathrm{mph}$ and $5.4 \mathrm{mph}$, showed similar patterns during $20 \mathrm{~min}$ walking.

Figure 4 shows the $\mathrm{MSE}_{2 \mathrm{D}}$ values at the $1^{\text {st }}$ min during 3 walking speeds. It was found that $\mathrm{MSE}_{2 \mathrm{D}}$ values of plantar pressure after $1.8 \mathrm{mph}$ walking were lower than those at $3.6 \mathrm{mph}$ and $5.4 \mathrm{mph}\left(\tau=1, \tau_{1.8 \mathrm{mph}}\right.$ vs. $\tau_{3.6 \mathrm{mph}}=0.296$ vs. $0.304, \tau_{1.8 \mathrm{mph}}$ vs. $\tau_{5.4 \mathrm{mph}}=0.296$ vs. $0.305 ; \tau=2, \tau_{1.8 \mathrm{mph}}$ vs. $\tau_{3.6 \mathrm{mph}}=0.360$ vs. $0.364, \tau_{1.8 \mathrm{mph}}$ vs. $\tau_{5.4 \mathrm{mph}}=0.360$ vs. 0.364 , $p<0.05)$.

Figure 5 shows the complexity index of plantar pressure images at the $1^{\text {st }}$ min during 3 walking speeds. The $\mathrm{CI}$ values increased significantly $\left(\mathrm{CI}_{1.8 \mathrm{mph}}\right.$ vs. $\mathrm{CI}_{3.6 \mathrm{mph}}=1.780$ vs. $1.790, p<0.05 ; \mathrm{CI}_{1.8 \mathrm{mph}}$ vs. $\mathrm{CI}_{5.4 \mathrm{mph}}=1.780$ vs. 1.792 , $p<0.05)$. 


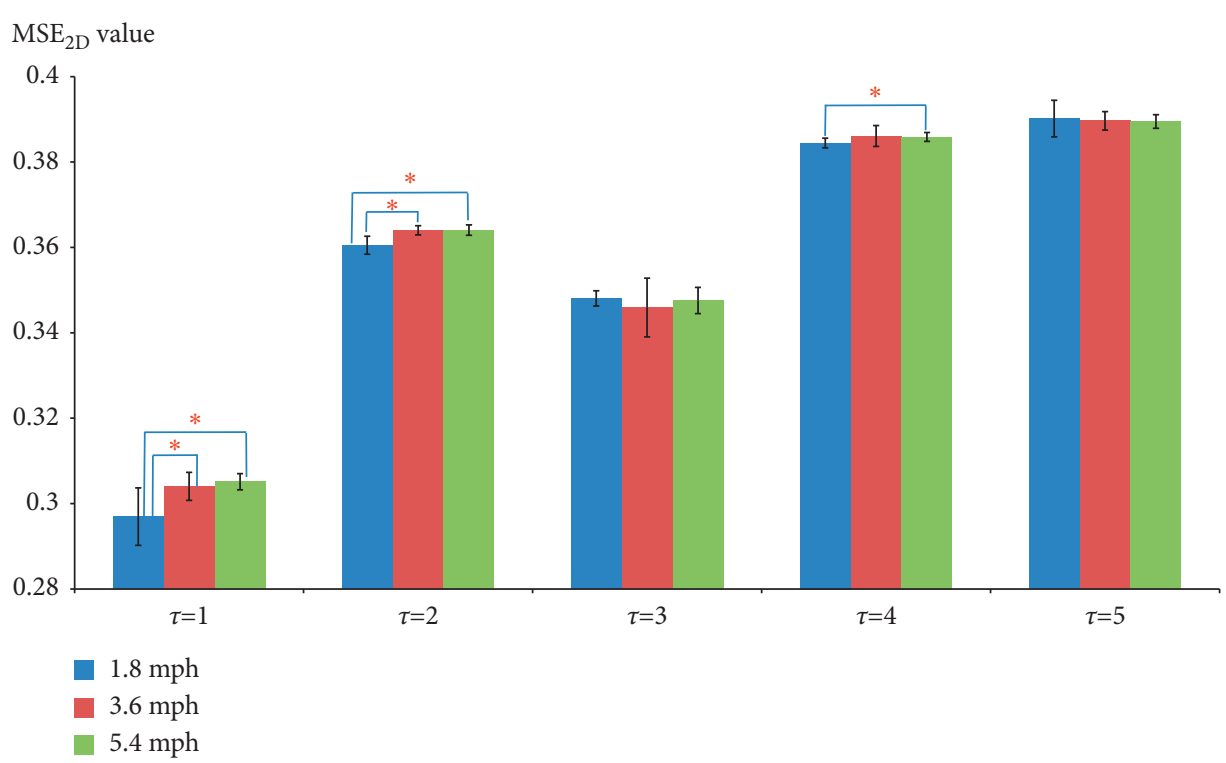

FiguRE 4: $\mathrm{MSE}_{2 \mathrm{D}}$ values of plantar pressure images from the time scales $\tau=1$ to 5 at the $1^{\text {st }}$ min during three walking speeds (1.8, 3.6, and $5.4 \mathrm{mph}) .{ }^{*}$ indicates $p<0.05$.

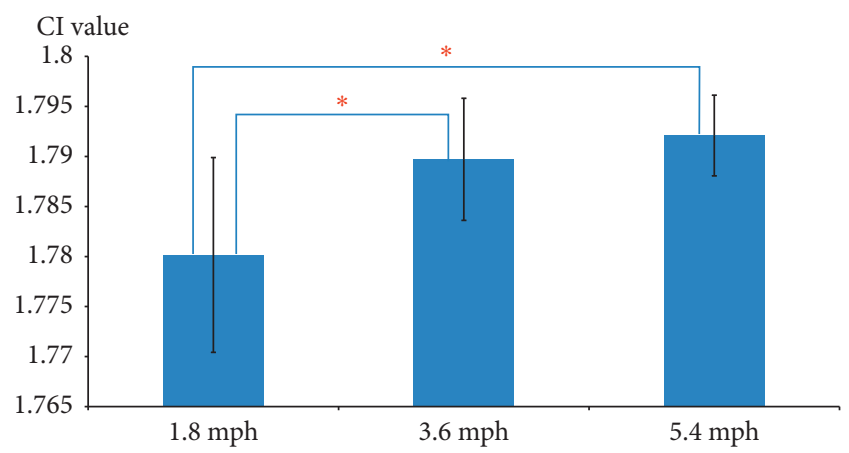

Figure 5: Complexity index of plantar pressure images at the $1^{\text {st }}$ min during three walking speeds $(1.8,3.6$, and $5.4 \mathrm{mph})$. *indicates $p<0.05$.

\section{Discussion}

Bidimensional multiscale entropy was used to assess the complexity of plantar pressure patterns after walking at different speeds for the first time. Our results showed that the complexity index (CI) values of walking at $1.8 \mathrm{mph}$ were significantly lower in the beginning compared with after 20 min walking; and waking at 3.6 and $5.4 \mathrm{mph}$ did not significantly change after 20 min walking. The finding of this study does not support our hypothesis that fast walking speeds would reduce complexity of plantar pressure images. Although the exact meaning cannot be quantified through this study, our results show that slow walking $(1.8 \mathrm{mph})$ may not be good for postural control given its low complexity index. Our study provide the first evidence that complexity of plantar pressure patterns changes after walking at different speeds.

According to the results by $\mathrm{MSE}_{2 \mathrm{D}}$ analysis in this study, it reveals that the $\mathrm{MSE}_{2 \mathrm{D}}$ values increased with longer walking duration $(p<0.05)$ when time scale $\tau=1$ and 2 at the $1.8 \mathrm{mph}$ walking speed but not in other speeds. Moreover, our study showed that $\mathrm{MSE}_{2 \mathrm{D}}$ values of plantar pressure after $20 \mathrm{~min}$ walking at $1.8 \mathrm{mph}$ were higher than those at $3.6 \mathrm{mph}$ and $5.4 \mathrm{mph}(p<0.05)$ when $\tau=1$ and 2 at the $1^{\text {st }}$ min (the beginning of the walking). Therefore, $\mathrm{MSE}_{2 \mathrm{D}}$ analysis could be used to investigate the difference of complexity of plantar pressure patterns during walking. Simultaneously, CI value increased with walking speed significantly $(p<0.05)$ at $1.8 \mathrm{mph}$ walking speed at the $1^{\text {st }} \mathrm{min}, 10^{\text {th }} \mathrm{min}$, and $20^{\text {th }} \mathrm{min}$. According to the previous study, normal walking has the highest complexity comparing with slow and fast walking speed [27]. Therefore, it may be speculated that slow walking at $1.8 \mathrm{mph}$ may not be a good speed for postural control for its low complexity index. On the other hand, after $20 \mathrm{~min}$ walking, the CI values increased significantly $(p<0.05)$ at $1.8 \mathrm{mph}$. This may be speculated that after sufficient walking time (i.e., 20 minutes in this study), the subjects learned how to walk at this slower speed and improve the postural control (higher complexity index at the end of 20 min walking).

In the application of medical image processing (plantar pressure distributions in this study (Figure 1)), the main purpose of medical image preprocessing is to enhance detection of image features. Usually, it is performed by the pixel in the space domain or the spectrum in the frequency domain, such as image averaging filter, spatial filter, histogram equalization, image subtraction, image segmentation, threshold method, region growing, and morphology [28]. The "entropy" concept is from thermodynamics to evaluate text feature, such as structural difference or complexity. Image recognition techniques could distinguish specific characteristics of an image and extract useful data from the image. The ways of image characteristic recognition may include minimum distance classification, fuzzy classification method, neural network, and model training [29]. Because spatial frequency components of the image 
information are nonlinear, the linear method may have limitations to detect these nonlinear features of the image. Because most biological systems are complex, nonlinear methods, such as bidimensional multiscale entropy, should be used $[19,20]$.

Traditional linear plantar pressure analysis has been widely used to investigate how walking speed influences the gait pattern, showing that peak plantar pressure globally elevates with increasing walking speed [30-34]. Moreover, some linear parameters calculated from COP are also proposed to potentially predict the risk of falls [35-38]. Regarding nonlinear plantar pressure analysis, our previous work used the one-dimensional MSE method to analyze COP, demonstrating similar results. The findings suggested that complexity of COP was significantly lower at $3 \mathrm{~km} / \mathrm{h}$ walking than the one at $6 \mathrm{~km} / \mathrm{h}$ [39]. The previous literature also endorsed the results that walking faster with shorter step length might improve stability [40,41]. People with poor postural and balance control (e.g., older people) would prefer to walk more slowly with shorter step length, which might be a detriment for walking stability [42-44]. The current study might be the first one to analyze the plantar pressure distribution with bidimensional MSE, which suggests that evaluating postural control by this method might be useful to provide valuable knowledge except traditional linear analysis. Linear analysis of plantar pressure is still important in patients with significantly poor postural control, but such complexity analysis might be useful for monitoring early impairments of postural control.

The current findings showing that complexity of plantar pressure images of walking at $1.8 \mathrm{mph}$ was significantly lower compared with walking at 3.6 and $5.4 \mathrm{mph}$ could be implanted into current clinical practice. For people with postural control issues, we would like to recommend these people to walk faster to improve postural control rather than walk slowly based on plantar pressure distribution patterns. In this study, a plantar pressure measurement system was used to measure plantar pressure during various walking activities in a laboratory setting. However, recent studies have demonstrated the feasibility of using low-cost portable systems for monitoring plantar pressure and person identification $[45,46]$. These systems will allow researchers to monitor real-life physical activities in people at risk for falls. Traditional linear analyses of plantar pressure such as peak plantar pressure and regional distribution ratios (forefoot versus rear foo) have been proposed in these low-cost systems. The bidimensional multiscale entropy method used in this study can be integrated into those systems for improving the detection of pathological gait by characterizing nonlinear features of plantar pressure [47]. The latest physical activity guideline published by World Health Organization (WHO) also recommends adults and older people to perform moderate to vigorous exercise weekly [48]. Therefore, recommending people to walk faster not only helps postural control but also enhances cardiovascular health.

There are limitations of this study. First, we recruited healthy subjects in this study rather than pathological patients. It is unclear about the interactions between pathological conditions (e.g., aging and diabetic neuropathy) and walking conditions (e.g., various walking speeds and durations) on the complexity of plantar pressure patterns. Future studies may recruit patient populations. Second, the duration of walking in this study was 20 minutes. Future studies may examine a longer walking duration that occurs in daily activities.

\section{Conclusions}

Bidimensional multiscale entropy was used to analyze the plantar pressure images under different walking speeds after 20 min walking for the first time. Our results showed that bidimensional multiscale entropy is useful to characterize the changes of the complexity of plantar pressure patterns. According to the results, it showed that walking speed at $1.8 \mathrm{mph}$ may not be beneficial for postural control due to its low complexity index compared with 3.6 and $5.4 \mathrm{mph}$. This study demonstrates that bidimensional multiscale entropy is a tool to assess plantar pressure changes after various walking speeds.

\section{Data Availability}

The data used to support this study are available from the corresponding author upon a reasonable request.

\section{Conflicts of Interest}

The authors declare that there are no conflicts of interest.

\section{References}

[1] B. Gow, C.-K. Peng, P. Wayne, and A. Ahn, "Multiscale entropy analysis of center-of-pressure dynamics in human postural control: methodological considerations," Entropy, vol. 17, no. 12, pp. 7926-7947, 2015.

[2] X. Hu, J. Zhao, D. Peng, Z. Sun, and X. Qu, "Estimation of foot plantar center of pressure trajectories with low-cost instrumented insoles using an individual-specific nonlinear model," Sensors, vol. 18, no. 2, 2018.

[3] C.-W. Huang, P.-D. Sue, M. Abbod, B. Jiang, and J.-S. Shieh, "Measuring center of pressure signals to quantify human balance using multivariate multiscale entropy by designing a force platform," Sensors, vol. 13, no. 8, pp. 10151-10166, 2013.

[4] P. C. Fino, A. R. Mojdehi, K. Adjerid, M. Habibi, T. E. Lockhart, and S. D. Ross, "Comparing postural stability entropy analyses to differentiate fallers and non-fallers," Annals of Biomedical Engineering, vol. 44, no. 5, pp. 1636$1645,2016$.

[5] M. A. Busa, S. L. Jones, J. Hamill, and R. E. A. van Emmerik, "Multiscale entropy identifies differences in complexity in postural control in women with multiple sclerosis," Gait \& Posture, vol. 45, pp. 7-11, 2016.

[6] A. Hills, E. Hennig, M. McDonald, and O. Bar-Or, "Plantar pressure differences between obese and non-obese adults: a biomechanical analysis," International Journal of Obesity, vol. 25, no. 11, pp. 1674-1679, 2001.

[7] M. N. Orlin and T. G. McPoil, "Plantar pressure assessment," Physical Therapy, vol. 80, no. 4, pp. 399-409, 2000.

[8] F. Liao, B. D. Struck, M. MacRobert, and Y.-K. Jan, "Multifractal analysis of nonlinear complexity of sacral skin blood 
flow oscillations in older adults," Medical, \& Biological Engineering \& Computing, vol. 49, no. 8, pp. 925-934, 2011.

[9] Y.-K. Jan, F. Liao, G. L. Y. Cheing, F. Pu, W. Ren, and H. M. C. Choi, "Differences in skin blood flow oscillations between the plantar and dorsal foot in people with diabetes mellitus and peripheral neuropathy," Microvascular Research, vol. 122, pp. 45-51, 2019.

[10] F. Liao and Y.-K. Jan, "Nonlinear dynamics of skin blood flow response to mechanical and thermal stresses in the plantar foot of diabetics with peripheral neuropathy," Clinical Hemorheology and Microcirculation, vol. 66, no. 3, pp. 197210, 2017.

[11] M. Costa, A. L. Goldberger, and C. K. Peng, "Multiscale entropy analysis of complex physiologic time series," Physical Review Letters, vol. 89, no. 6, Article ID 068102, 2002.

[12] M. Costa, A. L. Goldberger, and C. K. Peng, "Multiscale entropy analysis of biological signals," Physical Review. E, Statistical, Nonlinear, and Soft Matter Physics, vol. 71, no. 2 Pt 1, Article ID 021906, 2005.

[13] A. Humeau-Heurtier, "The multiscale entropy algorithm and its variants: a review," Entropy, vol. 17, no. 5, pp. 3110-3123, 2015.

[14] M. Costa, A. L. Goldberger, and C. K. Peng, "Multiscale entropy to distinguish physiologic and synthetic RR time series," Computers in Cardiology, vol. 29, pp. 137-140, 2002.

[15] J. Escudero, D. Abásolo, R. Hornero, P. Espino, and M. López, "Analysis of electroencephalograms in Alzheimer's disease patients with multiscale entropy," Physiological Measurement, vol. 27, no. 11, pp. 1091-1106, 2006.

[16] A. Catarino, O. Churches, S. Baron-Cohen, A. Andrade, and H. Ring, "Atypical EEG complexity in autism spectrum conditions: a multiscale entropy analysis," Clinical Neurophysiology, vol. 122, no. 12, pp. 2375-2383, 2011.

[17] J. F. Valencia, A. Porta, M. Vallverdu et al., "Refined multiscale entropy: application to $24 \mathrm{~h}$ holter recordings of heart period variability in healthy and aortic stenosis subjects," IEEE Transactions on Biomedical Engineering, vol. 56, no. 9, pp. 2202-2213, 2009.

[18] S.-D. Wu, C.-W. Wu, S.-G. Lin, C.-C. Wang, and K.-Y. Lee, "Time series analysis using composite multiscale entropy," Entropy, vol. 15, no. 3, pp. 1069-1084, 2013.

[19] L. E. V. Silva, A. C. d. S. S. Filho, V. P. S. Fazan, J. Felipe, and L. O. Murta, "Two-dimensional sample entropy: assessing image texture through irregularity," Biomedical Physics \& Engineering Express, vol. 2, no. 4, 2016.

[20] L. E. V. Silva, J. J. Duque, J. C. Felipe, L. O. Murta Jr, and A. Humeau-Heurtier, "Two-dimensional multiscale entropy analysis: applications to image texture evaluation," Signal Processing, vol. 147, pp. 224-232, 2018.

[21] A. Humeau-Heurtier, A. C. M. Omoto, and L. E. V. Silva, "Bidimensional multiscale entropy: relation with discrete fourier transform and biomedical application," Computers in Biology and Medicine, vol. 100, pp. 36-40, 2018.

[22] B.-Y. Liau, F.-L. Wu, K. Zhang, C.-W. Lung, C. Cao, and Y.-K. Jan, "Using bidimensional multiscale entropy analysis of ultrasound images to assess the effect of various walking intensities on plantar soft tissues," Entropy, vol. 23, no. 3, p. 264, 2021.

[23] P. C. Raffalt, W. Denton, and J. M. Yentes, "On the choice of multiscale entropy algorithm for quantification of complexity in gait data," Computers in Biology and Medicine, vol. 103, pp. 93-100, 2018

[24] F.-L. Wu, W. T.-J. Wang, F. Liao, J. Elliott, S. Jain, and Y.-K. Jan, "Effects of walking speeds and durations on plantar skin blood flow responses," Microvascular Research, vol. 128, Article ID 103936, 2020.

[25] C.-W. Lung, E. T. Hsiao-Wecksler, S. Burns, F. Lin, and Y.-K. Jan, "Quantifying dynamic changes in plantar pressure gradient in diabetics with peripheral neuropathy," Frontiers in Bioengineering and Biotechnology, vol. 4, p. 54, 2016.

[26] H. Azami, L. E. V. da Silva, A. C. M. Omoto, and A. HumeauHeurtier, "Two-dimensional dispersion entropy: an information-theoretic method for irregularity analysis of images," Signal Processing: Image Communication, vol. 75, pp. 178-187, 2019.

[27] M. Costa, C.-K. Peng, G. Ary, and J. M. Hausdorff, "Multiscale entropy analysis of human gait dynamics," Physica A-Statistical Mechanics and Its Applications, vol. 330, no. 1-2, pp. 53-60, 2003.

[28] A. P. Dhawan, Medical Image Analysis, Vol. 31, John Wiley \& Sons, Hoboken, NJ, USA, 2011.

[29] R. C. Gonzalez and R. E. Woods, Digital Image Processing, Prentice-Hall, Bergen, NJ, USA, 2002.

[30] D. Rosenbaum, S. Hautmann, M. Gold, and L. Claes, "Effects of walking speed on plantar pressure patterns and hindfoot angular motion," Gait \& Posture, vol. 2, no. 3, pp. 191-197, 1994.

[31] A. Segal, E. Rohr, M. Orendurff, J. Shofer, M. O'Brien, and B. Sangeorzan, "The effect of walking speed on peak plantar pressure," Foot \& Ankle International, vol. 25, no. 12, pp. 926-933, 2004.

[32] M.-J. Chung and M.-J. Wang, "Gender and walking speed effects on plantar pressure distribution for adults aged 20-60 years," Ergonomics, vol. 55, no. 2, pp. 194-200, 2012.

[33] J. M. Burnfield, C. D. Few, O. S. Mohamed, and J. Perry, "The influence of walking speed and footwear on plantar pressures in older adults," Clinical Biomechanics, vol. 19, no. 1, pp. 78-84, 2004.

[34] G. L. Warren, R. M. Maher, and E. J. Higbie, "Temporal patterns of plantar pressures and lower-leg muscle activity during walking: effect of speed," Gait \& Posture, vol. 19, no. 1, pp. 91-100, 2004.

[35] I. Melzer, N. Benjuya, and J. Kaplanski, "Postural stability in the elderly: a comparison between fallers and non-fallers," Age and Ageing, vol. 33, no. 6, pp. 602-607, 2004.

[36] A. Merlo, D. Zemp, E. Zanda et al., "Postural stability and history of falls in cognitively able older adults: the canton ticino study," Gait \& Posture, vol. 36, no. 4, pp. 662-666, 2012.

[37] C. A. Laughton, M. Slavin, K. Katdare et al., "Aging, muscle activity, and balance control: physiologic changes associated with balance impairment," Gait \& Posture, vol. 18, no. 2, pp. 101-108, 2003.

[38] T. E. Prieto, J. B. Myklebust, R. G. Hoffmann, E. G. Lovett, and B. M. Myklebust, "Measures of postural steadiness: differences between healthy young and elderly adults," IEEE Transactions on Biomedical Engineering, vol. 43, no. 9, pp. 956-966, 1996.

[39] B.-Y. Liau, F.-L. Wu, C.-W. Lung, X. Zhang, X. Wang, and Y.-K. Jan, "Complexity-based measures of postural sway during walking at different speeds and durations using multiscale entropy," Entropy, vol. 21, no. 11, p. 1128, 2019.

[40] T. Bhatt, J. D. Wening, and Y.-C. Pai, "Influence of gait speed on stability: recovery from anterior slips and compensatory stepping," Gait \& Posture, vol. 21, no. 2, pp. 146-156, 2005.

[41] P. M. McAndrew Young and J. B. Dingwell, "Voluntarily changing step length or step width affects dynamic stability of human walking," Gait \& Posture, vol. 35, no. 3, pp. 472-477, 2012. 
[42] H. B. Menz, S. R. Lord, and R. C. Fitzpatrick, "Age-related differences in walking stability," Age and Ageing, vol. 32, no. 2, pp. 137-142, 2003.

[43] F. Stief, A. Schäfer, L. Vogt et al., "Differences in gait performance, quadriceps strength, and physical activity between fallers and nonfallers in women with osteoporosis," Journal of Aging and Physical Activity, vol. 24, no. 3, pp. 430-434, 2016.

[44] P. DeVita and T. Hortobagyi, "Age causes a redistribution of joint torques and powers during gait," Journal of Applied Physiology (1985), vol. 88, no. 5, pp. 1804-1811, 2000.

[45] T. Keatsamarn, S. Visitsattapongse, H. Aoyama, and C. Pintavirooj, "Optical-based foot plantar pressure measurement system for potential application in human postural control measurement and person identification," Sensors, vol. 21, no. 13, 2021.

[46] P. H. Truong, S. You, S. H. Ji, and G. M. Jeong, "Adaptive accumulation of plantar pressure for ambulatory activity recognition and pedestrian identification," Sensors, vol. 21, no. 11, 2021.

[47] B. Zhang and Q. Lu, "A current review of foot disorder and plantar pressure alternation in the elderly," Physical Activity and Health, vol. 4, no. 1, pp. 95-106, 2020.

[48] F. C. Bull, S. S. Al-Ansari, S. Biddle et al., "World health organization 2020 guidelines on physical activity and sedentary behaviour," British Journal of Sports Medicine, vol. 54, no. 24, pp. 1451-1462, 2020. 